\title{
Students' Expectation for Educational Quality: Progressive Participatory Discussion Teaching with Effect and Confirmatory Factor Analysis
}

\author{
Wang Peng* \\ School of Ethnology and Sociology \\ Inner Mongolia University \\ Hohhot, China
}

\begin{abstract}
The teaching method is a tool-box that promotes effective teaching and learning to meet the needs. It should be a mixture of multiple teaching methods and teaching strategies. For solving the problems in teaching practice, combining of various teaching methods contributes to achieve student-centered development. Progressive participatory discussion teaching emphasizes the dual subjectivity and constructiveness of teachers and students in the process of setting, implementing and evaluating teaching objectives, and pays attention to students' participation and experience in teaching practice. The results of the Amos model confirmatory analysis based on the teaching quality survey data show that the progressive participatory discussion teaching can effectively promote the learning effect of students as the subject of learning, and the improvement of teaching methods makes that the students as the subject of learning have higher expectation to teacher as the subject of teaching.
\end{abstract}

Keywords-Progressive Education; Participatory Discussion; Dual subjectivity; Amos

\section{INTRODUCTION}

In recent years, there has been a boom in the construction of first-class universities in China's higher education. Education reform is an important part of the construction of first-class universities. Besides, the teaching method is a hot topic in education reform. Many teaching paradigms or methods have been discussed, such as Seminar, case teaching, PBL (Problem-Based Learning), participatory teaching, flipped classroom, teaching blending, experiential teaching, and stepby-step teaching. These teaching methods show some characteristics: a. Students' development as the teaching center [1]; b. Guided by questions [2]; c. Discussion as the teaching method [3]; d. Take participation and experience as teaching practice [4]; e. Take progressive stage and cognitive learning autonomy as the teaching motivation; f. Take teaching blending as the new teaching paradigm [5].

Progressive participatory discussion teaching proposed in this paper is not only a comprehensive application of the previous teaching methods, but also a summary of the author's experience in solving the teaching problems and improving the teaching effect in the teaching practice. For the innovation of teaching methods, it is necessary to integrate and apply the

Sponsor: Supported by the teaching reform research and construction project of Inner Mongolia University. advantages of various teaching methods. At the same time, it is also necessary to take measures in accordance with local conditions to promote progressive innovation, rather than one size fits all [6].

Some teaching problems are highlighted in teaching practice. For example, students lack the sense of achievement in learning; The organic cooperation degree of students' cooperative learning group is not high; The assessment method of course performance is single; Students lack the opportunity to change the cognitive model and improve the reflective ability; In the course teaching, the subjective expression of students is not obvious in the aspects of course evaluation index, learning incentive method and learning initiative. In view of the above problems in teaching practice, this paper tries to use progressive participatory discussion teaching and demonstrate the feasibility of solving these problems by means of empirical research.

What is progressive participatory discussion teaching? It is based on the student development as the center, a mixture of the use of autonomous cognitive learning, progressive teaching, experiential teaching, participatory teaching and discussion teaching methods. Moreover, drawing on the method of management by objectives proposed by Peter $\mathrm{f}$. Drucker in his book The Practice of Management, the teaching objectives of the curriculum and students' autonomous learning objectives are gradually integrated, so as to promote the realization of the objective of double subject between teachers and students in the teaching practice.

Progressive participatory discussion teaching emphasizes the following characteristics: dual subjectivity of teaching objectives; Cooperative construction of teaching objectives; The participation and experience of teaching practice; The improvement of teaching arrangement and the generation of teaching evaluation. The strategies it implements in teaching practice are as follows: first, the teaching objective is studentoriented, and the teaching objective system embodies the double subjectivity of teachers and students, so as to enhance the teaching experience of teaching-learning-practice innovation; Secondly, teaching practice includes four stages: introduction, demonstration, autonomy and sharing. At the same time, in order to meet the needs of students' cognitive 
learning autonomy, the latter stage reflects on the former stage to improve the teaching content and methods. Finally, the strategies of teaching method implementation include innovative practice method, innovative cooperation method and innovative demand method [7].

\section{METHODS AND RESUlT}

\section{A. Data Collection Index and Application of Likert Scale}

Progressive participatory discussion teaching is actually centered on the development of students, and its teaching effect is more directly reflected in the effect of students' learning cognition, practical experience and ability improvement. Therefore, this paper defines the teaching effect of progressive participatory discussion as the learning effect of students' selfassessment, including the ability of learning demand, the ability of cooperation and the ability of practice.

The research data was based on the teaching quality survey of an autumn semester course of Inner Mongolia University taught by the author. Data was collected using a Likert Scale (very good, good, average, poor, very poor). The sample was of all students in this course. The sample size was 53. Basic information of the sample: the respondents were all juniors. The gender distribution was 8 male students and 45 female students, and the female sample accounted for $84.9 \%$ of the total sample.

The learning effect of students includes three index: learning demand ability, cooperative ability and practical ability. Index and variables are shown in Fig.1.

\begin{tabular}{|c|c|c|}
\hline Latent variahle & lodkx & Obecrvation suriahile \\
\hline \multirow{15}{*}{$\begin{array}{l}\text { Learning Fffect } \\
\text { (LE) }\end{array}$} & \multirow{5}{*}{ Leaming demand ability } & Active learning involvement (a) 1) \\
\hline & & Clasarocm teaching involemement $(a 2)$ \\
\hline & & Leaming interst eshasecmemt (a.3) \\
\hline & & Professical imterest enhancement (a4) \\
\hline & & Persomal quality enhanoement (a5) \\
\hline & \multirow{5}{*}{ Cooperative ability } & Expscted classroom participation (m6) \\
\hline & & Allention to classooen explanation $\{a 7\}$ \\
\hline & & Altention to classroom means (a8) \\
\hline & & Partisipaticat in dhesussion and evaluation (a9) \\
\hline & & Participatinn in cooperatian (alo) \\
\hline & \multirow{5}{*}{ Practical abitity } & Mastery of leaning coentent (alli) \\
\hline & & Method of analyzieu rockikms (a) 2) \\
\hline & & Slating of learning experictice (a I3) \\
\hline & & Degree of endentandies and reflection $(a 14)$ \\
\hline & & Realizatice of persomal gouls (o15) \\
\hline
\end{tabular}

Fig. 1. The measurement index and observation variables of students' learning effect.

\section{B. Descriptive Statistics of Student Learning Effect}

According to the statistical results of SPSS based on the survey data, in terms of learning demand ability, the five observation variables with very good and good evaluation accounted for $83.0 \%, 69.2 \%, 67.9 \%, 62.3 \%$ and $88.7 \%$. The cumulative upward percentages of the average evaluation of the five observation variables were all above $96.2 \%$.

In terms of cooperative ability, the five observation variables with very good and good evaluation accounted for $66.0 \%, 50.9 \%, 71.7 \%, 73.6 \%$ and $71.7 \%$. The cumulative upward percentages of the average evaluation of the five observation variables were all above $90.6 \%$

In terms of cooperative ability, the five observation variables with very good and good evaluation accounted for $62.3 \%, 67.9 \%, 67.9 \%, 79.2 \%$ and $77.4 \%$. The cumulative upward percentages of the average evaluation of the five observation variables were all above $94.3 \%$.

From the statistical results of students' self-assessment of learning effect, it can be seen that the application of progressive participatory discussion teaching can effectively enhance students' learning motivation and guide them to actively participate in the learning process of pre-class preparation, classroom learning and after-class review. It has an obvious promoting effect on the improvement of learning interest in courses and majors, as well as improvement of students' quality.

At the same time, progressive participatory discussion teaching can cultivate students' ability to cooperate, which can obviously encourage students to participate in classroom discussion, classroom explanation, and the mixed use of various classroom explanation means such as video and network media. The students gave a high evaluation on the effect of participating in the discussion and cooperation.

In addition, progressive participatory discussion teaching can better improve students' practical ability. The students can use the course knowledge to understand, analyze and reflect on social practice, and share the learning and practical experience, which is conducive to promoting students to realize their personal learning and practice objectives in combination with the course teaching objectives.

\section{Teaching Effect Model and Confirmatory Factor Analysis}

What are the factors that influence the teaching effect? This paper holds that the dual subject design of teaching objectives and the mixed application of various teaching methods have a direct impact on the learning effect of students' self-assessment At the same time, research results show that students have higher requirements for teachers' teaching performance and guidance. Amos is used in this paper to test the hypothesis of influencing factors of teaching effect.

In the research hypothesis, the three latent variables are students' learning effect, progressive participatory discussion teaching and teacher's teaching guidance. In addition to the latent variables of students' learning effect, the measurement index and observation variables of the other two latent variables are shown in Fig.2. 


\begin{tabular}{|c|c|c|}
\hline Latant variables & Indas & Otwervation variahle \\
\hline \multirow{10}{*}{$\begin{array}{l}\text { Rogressive participabory } \\
\text { discussien tesching (PD) }\end{array}$} & \multirow{3}{*}{ Progroxsive purticipation } & Qheotios and answer design (b1) \\
\hline & & Cave teaching $(b 2)$ \\
\hline & & Subjextivity leachine (b3) \\
\hline & \multirow{3}{*}{ Rurbipatary discussion } & Group distussiom (bel) \\
\hline & & Cwe partivipatim (b5) \\
\hline & & Dual abjactivisy facusaba (b6) \\
\hline & \multirow{4}{*}{ Multiple cialuation } & Group ers taatioe (b7) \\
\hline & & Presonal evaluation (bs) \\
\hline & & 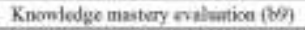 \\
\hline & & Stultiple componition of igrades tb 109 \\
\hline \multirow{9}{*}{ Teaching gudance (TG) } & \multirow{3}{*}{ Teacting propurative } & Teacher appeannee (e) \\
\hline & & Teaslter kawilalge prijuratios (e2) \\
\hline & & Course diffically velting (3) \\
\hline & \multirow{3}{*}{ Teaching conzmanication } & Teacher vathal exprositie (04) \\
\hline & & Eacratiun (5) \\
\hline & & Active ctassnoom (c6) \\
\hline & \multirow{3}{*}{ Tenching methods } & Multiple measen of esplanation (c) \\
\hline & & Feaubar-ked discussicen (s5) \\
\hline & & Continasus improvenedi (es) \\
\hline
\end{tabular}

Fig. 2. The measurement index and observation variables of progressive participatory discussion and teacher teaching guidance.

In order to trust the reliability of the collected data, the reliability analysis was carried out on the observation variables of three latent variables, namely, student learning effect, progressive participatory discussion teaching, and teacher teaching guidance. Generally speaking, the standardized Items of Cronbach's $\alpha$ (coefficient value between 0 and 1) is used to analyze the reliability of data. When the value is higher than 0.6 , the data is considered to be reliable; and when the value is higher than 0.8 , the data is considered to be highly reliable. Based on the analysis of SPSS data, the values of Cronbach's $\alpha$ of the three latent variables were $0.929,0.874$ and 0.837 . Therefore, it can be considered that the observation variable data of the three parts have high reliability.

The test results of the Amos confirmatory analysis model of the three latent variables are shown in Fig.3. Maximum Likelihood estimation (ML) is firstly used for model adaptation estimation. In Fig.3, there is no standardized regression coefficient greater than 1 , that is, no improper values are interpreted. In terms of model fitness test, the chi-square degree of freedom ratio was $1.947(<2.000)$, and RMSEA value was 0.135 (not conforming to the fitness standard of less than 0.08 ). It was assumed that the fitness degree between the model and sample data was poor. The reason may be that the estimated sample size of Amos model is generally more than 100, and the small sample size will lead to the instability of model adaptation.

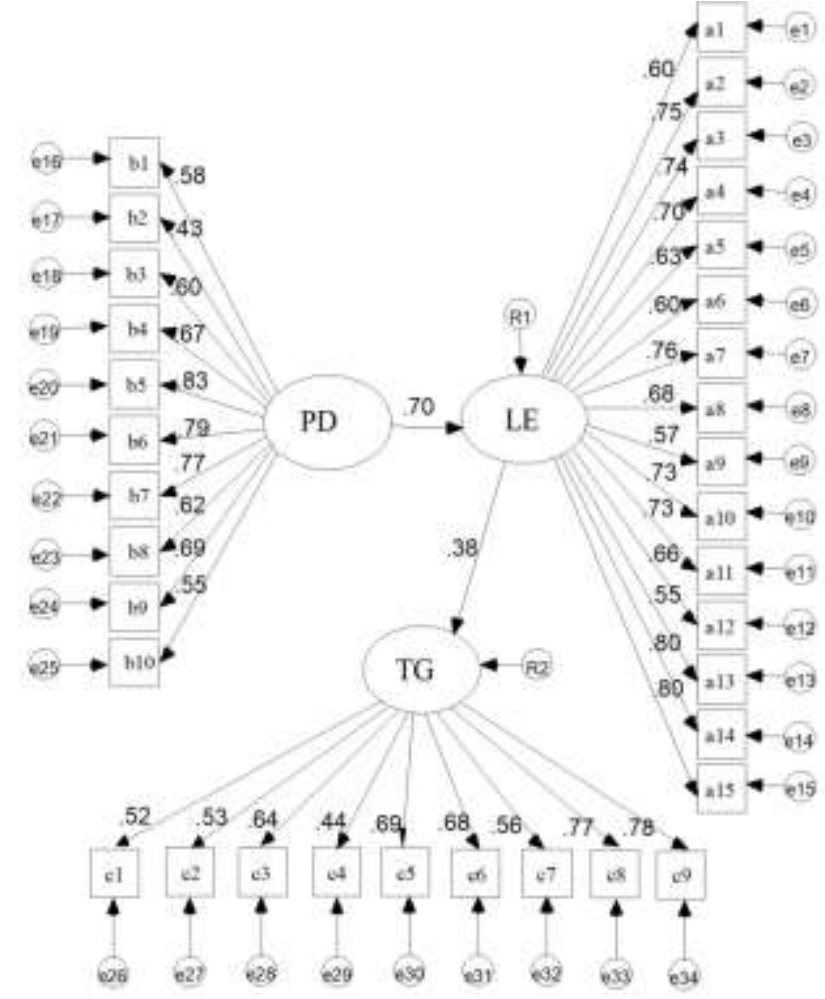

Fig. 3. Confirmatory analysis of teaching effect model.

Therefore, in the case of small samples, Bayesian estimation is generally used for model estimation. Markov Chain Monte Carlo (MCMC) estimated the total population for sample generation, and the number of samples generated was 13,500, Convergence statistic (C.S.) value was $1.0244(<1.1)$. The model adaptation index of Bayesian estimation was Posterior predictive $\mathrm{p}$, and in the model $\mathrm{p}=0.51(0.05<\mathrm{p}<$ 0.95 ; When $\mathrm{p}$ close to 0.05 , it means that the model fits well). The standardized path coefficient value of the teaching effect model is as follows: the coefficient value of PD to LE is 0.683 ; The coefficient value of LE to TG is 0.310 .

The results show that the application of progressive participatory discussion teaching has a significant effect on the improvement of students' learning effect. But the student is not only the teacher teaching object, the student learning effect improvement will put forward the higher request to how to teach.

\section{CONCLUSION}

The progressive participatory discussion teaching is the summary of the author's teaching practice experience. It does not have the universal significance of the wide application of method, but in the teaching practice, in order to effectively solve the specific practical problems of teaching and learning, the improvement of teaching methods based on local conditions has the universal characteristics.

The research shows that the application of progressive participatory discussion teaching can effectively promote the learning effect of students, including the improvement of learning demand ability, cooperative ability and practical 
ability. At the same time, students as the subject of learning have higher expectations for the subject of teachers' teaching.

\section{REFERENCES}

[1] Jin lei Zhang, Research on the key factors of the teaching model of flipped classroom, in Distance Education in China, No.10, Beijing: The Open University of China, pp.59-64, 2013. (In Chinese).

[2] Liu Yang, Problems and solutions with PBL mode in medical education, in Basic Medical Education, vol. 17 No. 8, Taiyuan: Shanxi Medical University, pp.694-696, Aug. 2015. (In Chinese).

[3] Qi min Ma, The Structure, Functions and Characteristics of seminar and its Implications to Liberal Arts Instruction in China, in International and
Comparative Education, No. 2, Beijing: Beijing Normal University, pp.20-23, 2003. (In Chinese).

[4] Jian guang Yao, Participatory teaching: theoretical construction and empirical samples, In Journal of the Chinese Society of Education, No. 1, Beijing: The Chinese Society of Education, pp.54-56, 2011. (In Chinese)

[5] Shi yu Liu, etc., Promoting the Innovation of University Teaching in the Integration of MOOCs and Discussion Teaching, in China Higher Education Research, No. 7, Beijing: China Association of Higher Education, pp.107-110, 2015. (In Chinese).

[6] Cheng Rong, Innovation and progressive general education have become the inevitable trend of university curriculum reform and talent training, in Journal of Southwest University for Nationalities (Humanities and Social Science), Vol. 34 No. 12, Chengdu: Southwest Minzu University, pp.205-208, 2013. (In Chinese).

[7] Wang Peng, Research on gradual participation discussion for teaching model reform, in Research in Teaching, Vol. 42 No. 3, Qinhuangdao: Yan Shan University, pp. 58-62, May. 2019. (In Chinese). 